\title{
Differentiating Incident from Recurrent Stroke Using Administrative Data: The Impact of Varying Lengths of Look-Back Periods on the Risk of Misclassification
}

\author{
John Mark Worthington ${ }^{a-c}$ Melina Gattellari ${ }^{b}$ Chris Goumas $^{b}$ \\ Bin Jalaludin ${ }^{b}, \mathrm{~d}, \mathrm{e}$

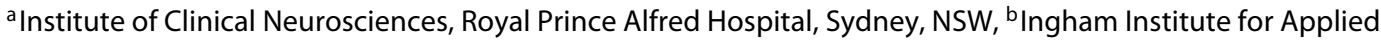 \\ Medical Research, Liverpool, NSW, ' South Western Sydney Clinical School, UNSW, Sydney, NSW, d South Western \\ Sydney Local Health District, Liverpool, NSW, and e School of Public Health and Community Medicine, UNSW, \\ Sydney, NSW, Australia
}

\section{Keywords}

Stroke $\cdot$ Administrative data $\cdot$ Methods $\cdot$ Epidemiology

\begin{abstract}
Background/Aims: Administrative data are widely used to monitor epidemiological trends in stroke and outcomes; yet there is scant empirical guidance on how to best differentiate incident from recurrent stroke. Methods: We identified all hospital admissions in New South Wales, Australia, with a principal stroke diagnosis from July 1, 2013 to June 30, 2014, linked to 12 years of previous admissions. We calculated the proportion of cases identified with a prior stroke to determine the number of years of look-back required to minimise misclassification of incident and recurrent strokes. Results: Using the maximum available look-back period of 12 years, 1,171 out of 8,364 eligible stroke cases (14.0\%) had a stroke history. A 1 -year look-back period identified only $25.1 \%$ of these patients and 1 in 10 stroke cases were misclassified as incident. With a 10-year clearance period, less than 1 in 100 stroke cases were misclassified as incident. The risk of misclassification was lower in patients younger than 65 years and in those with haemorrhagic stroke. Conclusion: Hospital
\end{abstract}

๑) 2017 S. Karger AG, Basel administrative data sets linked to prior admissions can be used to distinguish recurrent from incident stroke. The risk of misclassifying recurrent stroke cases as incident events is negligible with a look-back period of 10 years.

(c) 2017 S. Karger AG, Basel

\section{Introduction}

Stroke is a leading cause of death and disability worldwide [1], placing a considerable burden on health services and community resources. Reliable data are required to inform the development and organisation of health services and assess the impact of changes in health care systems. Administrative data sets are widely used by researchers to cost effectively monitor epidemiological trends in stroke, evaluate stroke management and describe outcomes (e.g., [2-7]). In several jurisdictions, administrative data are legislated as mandatory collections providing a census of all hospitalisations. Linking routinely collected hospitalisation data to previous and subsequent admissions and death registrations enriches the information and creates longitudinal cohorts recording
Melina Gattellari

Ingham Institute for Applied Medical Research

1 Campbell Street

Liverpool, NSW 2170 (Australia)

E-Mail Melina.Gattellari@sswahs.nsw.gov.au 
medical history and patient outcomes including mortality, readmissions and access to in-hospital health services. These data sets, therefore, feasibly capture continuous information from large, representative, population-based patient cohorts.

Epidemiological studies reporting first-ever or incident stroke rates require valid determination of previous stroke. Linking admissions to prior hospitalisations can ascertain stroke history, obviating the need to rely on potentially unreliable patient reporting [8]. As data linkage becomes widespread, researchers and policymakers have the capacity to differentiate between incident and recurrent stroke. However, there is scant empirical guidance on how this should be done. Accurately identifying prior stroke depends on the extent to which admissions in previous years are available for linkage. A longer lookback period minimises misclassification of incident stroke and yet also reduces the possible size of cohorts. Hospitalisations comprising the look-period period are used to determine stroke history and therefore do not contribute cases for analysis. Therefore, data comprising the look-back period is used to inform patient medical history rather than to identify additional acute stroke cases. Additionally, stroke risk differs by age, gender, and sub-type and these variations in baseline risk might also have an impact on the required length of look-back periods.

We are currently undertaking an epidemiological study of stroke in New South Wales (NSW), Australia's most populous state using administrative data (current population estimated as 7.7 million) [9]. We aimed to explore stroke epidemiology in the context of established and emerging therapies for the primary and secondary prevention of stroke, wishing to differentiate incident from recurrent stroke in hospitalised acute stroke patients. Our focus was to establish a previous stroke history utilising hospitalisation data spanning a time period in excess of 10 years. We sought to examine the impact of varying look-back periods on the ascertainment of incident and recurrent stroke, aiming to identify look-back periods that would minimise misclassification of incident and recurrent stroke.

\section{Methods}

\section{Case Selection}

The admitted patient data collection (APDC) is a compulsory census of all hospital separations in NSW, including deaths in emergency departments [10], with data collated for each Australian financial year period (from July 1 to June 30 ). A hospital separation is an "administrative process" whereby hospitals record the "cessation of treatment and/or care and/or accommodation of the patient" [11]. The APDC collates demographic information, the principal diagnosis, up to 49 secondary diagnoses reflecting comorbidities, billable procedures, and allied health-care management undertaken during the admission. Discharge status, hospital characteristics, such as referral status, and dates and times of admission and discharge are also noted. The principal diagnosis is defined as the main condition responsible for the patient's admission [12]. Trained medical coders utilise standardised coding for diagnoses and procedures in accordance with well-defined coding standards to maximise accuracy and reliability [12]. Values for age and gender are rarely missing and were complete in the data set reported here. Principal diagnoses are missing only in $0.3 \%$ of recorded overnight separations for acute care [13]. Data is available from July 1, 2001.

This methodological sub-study was carried out as part of a larger programme of research, the Home to Outcomes study, an ongoing data-linkage study, addressing the epidemiology of stroke and the evaluation of stroke health service delivery. Patients aged 15 years or older with stroke diagnoses were identified. Data linkage was carried out by a government-funded provider of linkage services for health and mortality data sets. Using ethically approved gold standard privacy-preserving protocols, deterministic and probabilistic linkage enhanced by manual clerical review is conducted using patient identifiers to link information about individuals across and between data sets, creating a linkage key that can be utilised for individual research projects. False-positive and false-negative links are no more than 5 per 1,000 [14]. The falsepositive linkage rate for this project was no more than 5 per 1,000 records (result supplied to researchers), indicating that for every 10,000 individuals identified for a linkage project, linkage errors will have occurred for no more than 50 people.

Separations related to a single hospitalisation may comprise several episodes indicating transfers between geographically distinct facilities and intra-hospital transfers reflecting changes in the type of care received (e.g., from acute to non-acute care). We developed an algorithm to join contiguous episodes of care utilising admission and separation dates and times and discharge status. We considered episodes of care to be contiguous if separated by up to 24-h and those occurring on the same day or at the end of the next calendar day where an inter-hospital transfer was recorded or where 2 contiguous episodes of care were recorded by different health facilities $[7,15,16]$. Records from aged-care homes were excluded, as these do not universally report to the APDC and admissions to these facilities signal an end to acute hospital delivered services and a discharge to a permanent place of residence.

We identified all hospital admissions with at least one episode of care recording a principal diagnosis of all types of strokes (ICD10AM [12] I60.x, I61.x, I62.9, I63.x, I64, H34.1, H34.2) from July 1, 2013 to June 30, 2014. The first recorded stroke admission per patient during our defined study period was selected where more than one admission was identified; the first available stroke admission per patient was designated the "index admission." We excluded patients who were younger than 15 years of age, not residing in NSW, or whose principal stroke episode was recorded as a rehabilitation episode or if misclassification was suspected. Cases were considered to be misclassified if transferred from a hospital on the same day or at the end of the next day of admission where the re- 
ceiving hospital did not also record a principal stroke diagnosis [4, 16]. Cases discharged alive within $48 \mathrm{~h}$ were also excluded as presumed nonacute strokes consistent with similar criterion applied elsewhere $[4,6,17]$.

\section{Stroke History, Prevalence of Recurrent Stroke and}

Misclassification of Recurrent Stroke

A history of stroke was identified where a stroke code was recorded in any admission prior to the index stroke from July 1, 2001 to June 30, 2013. Therefore, a maximum clearance period of 12 years was available. All available 50 diagnostic codes were interrogated for stroke and stroke sequelae (ICD-10AM I69.0, I69.1; I69.3, I69.4). This sensitive definition of prior stroke did not require that the stroke occurred acutely during the look-back period, including strokes recorded as a preexisting condition or comorbidity and those not recorded as the principal reason for the admission. Ascertaining comorbidity burden via the APDC produces similar results as doing so using medical records [18]. The sensitivity, positive predictive value (PPV) and inter-rater agreement of cerebrovascular disease recorded as a comorbidity when validated against an "expert coder" were high in an Australian hospitalisation data set $(89 \%, 93 \%$ and kappa $=0.91$, respectively) [19]. The maximum available look-back of 12 years was the gold-standard against which other look-back periods were judged. We selected look-back periods of 1-, 3-, 5-, 8-, and 10-years predominately on a pragmatic basis.

For each look-back period, we calculated the prevalence of patients with recurrent stroke by dividing the number of recurrent cases captured in each look-back period by the total number of index stroke patients. We also calculated the proportion of patients correctly identified with a recurrent stroke by dividing the number of recurrent cases captured in that period by the total number of recurrent strokes identified using the maximum 12-year look-back period. We calculated the proportion of patients with recurrent stroke misclassified as incident for each look-back period. The numerator was the number of recurrent strokes that were detected in each look-back period subtracted from the number of patients with recurrent strokes identified using the maximum look-back 12 -year period. This difference, therefore, identified patients with recurrent strokes not detected during the respective look-back period and incorrectly classified as incident cases. The denominator was the number of cases thought to be incident strokes during each respective look-back period; that is, the number of patients with recurrent stroke detected during each look-back period subtracted from the numbers of index stroke cases. For all calculations, we assumed that the maximum available look-back period of 12-years provided a "gold standard" ascertainment of recurrent and incident stroke.

The impact of varying look-back periods on results was also examined according to the stroke sub-type, whereby stroke history was defined according to the sub-type of the index case. Index stroke admissions were classified as ischaemic stroke (I63, H34.1, H34.2) or haemorrhagic stroke (I60, I61, and I62.9). Where the first recorded stroke diagnosis in each admission was ICD-10 code I64, "stroke, not otherwise specified as haemorrhage or infarction," subsequent episodes of care recording a specific stroke diagnosis were interrogated to inform the sub-type; otherwise, I64 coded strokes were considered ischaemic strokes, as evidence in Australia indicates that these cases rarely represent haemorrhagic cerebrovascular events (1\%) or transient ischaemic attacks (2\%)

Differentiating Incident from Recurrent

Stroke Using Administrative Data
$[20,21]$. This approach is recommended in 2 recent systematic reviews of stroke coding validity to increase the sensitivity of ischaemic stroke sub-typing without compromising the PPV [22, 23].

Independent samples chi-square tests were used to test differences between 2 independent proportions using MedCalc software [24].

\section{Results}

\section{Case Selection}

We identified 9,768 admissions with a principal diagnosis of stroke from July 1, 2013 to June 30, 2014 of which 9,387 (96.1\%) were index admissions. We excluded 1,023 (10.9\%) index admissions due to ineligible age $(n=1)$, the patient residing outside NSW $(n=192 ; 2.0 \%)$, rehabilitation as the intent of treatment $(n=4)$, revision of the stroke diagnosis upon early transfer to another hospital $(n=293 ; 3.1 \%)$ and discharge within $48 \mathrm{~h}(n=533,5.7 \%)$, leaving 8,364 eligible index cases.

\section{Ascertainment of Stroke History, Prevalence of Recurrent Stroke and Misclassification of \\ Recurrent Stroke}

Using the maximum available look-back period of 12 years, 1,171 (14.0\%) patients had a prior history of stroke (Table 1). A 1-year look-back period identified 294 cases with a stroke history, representing only $25.1 \%$ of the ascertained 1,171 recurrent stroke cases. The prevalence of previous stroke using a 1-year look-back was estimated as 3.5\%. Applying a 3-year look-back period doubled the estimated prevalence of prior stroke to $7.5 \%$. With a 5 -year look-back, $10.0 \%$ of cases were recorded as having a previous stroke, representing $71.4 \%$ of the 1,171 patients with a stroke history identified using all available admissions in the 12-year look-back period. An 8 -year look-back period captured $88.6 \%$ of patients known to have a stroke history using a 12-year look-back period; by 10 years, this had increased to $94.7 \%$. The prevalence of previous stroke changed negligibly after 8 years, increasing in absolute terms by $1.6 \%$ and increased thereafter by only $0.7 \%$ from 10 to 12 years.

Using a 1-year look-back period, 294 admissions were correctly classified as patients with recurrent strokes and 8,070 were presumed incident cases. Given that 1,171 cases were known to be recurrent using a 12-year look-back period, 877 (i.e., 1,171 minus 294 ) or $10.9 \%$ of the presumed incident cases were actually recurrent strokes misclassified as incident. Using a 5-year look-back period, $334(4.4 \%)$ were misclassified as incident strokes, while 62 
Table 1. Effect of look-back on the prevalence and misclassification of incident and recurrent stroke

\begin{tabular}{|c|c|c|c|c|c|c|c|}
\hline 1-Year & 294 & 8,070 & 3.5 & 25.1 & 877 & 10.9 & 3.984 \\
\hline 3-Years & 629 & 7,735 & 7.5 & 53.7 & 542 & 7.0 & 1.862 \\
\hline 10-Years & 1,109 & 7,255 & 13.3 & 94.7 & 62 & 0.9 & 1.056 \\
\hline 12-Years & 1,171 & 7,193 & 14.0 & 100 & 0 & 0 & 1 \\
\hline Total stroke cases & 8,364 & & & & & & \\
\hline
\end{tabular}

\footnotetext{
${ }^{1}$ Calculated by dividing the number of patients with recurrent stroke identified during each look-back period by the total number of index stroke cases $(\mathrm{a} / 8,364)$.

${ }^{2}$ Calculated by dividing the number of patients with recurrent stroke identified during each look-back period by the total number of patients with recurrent stroke $(\mathrm{a} / 1,171)$.

${ }^{3}$ Calculated by subtracting the number of patients with a recurrent stroke identified for each look-back period from the total number of patients with recurrent stroke identified with 12-years' look-back $(1,171-\mathrm{a})$.

${ }^{4}$ Number of patients with recurrent stroke misclassified as incident per look-back period is the numerator. Number of patients with incident stroke per look-back period is the denominator $(\mathrm{e} / \mathrm{b})$.

${ }^{5}$ Indicating multiplicative factor to inflate numbers of patients with recurrent stroke to adjust for potential missed cases (100/d).
}

Table 2. Effect of look-back period on the prevalence of recurrent stroke and the proportion of recurrent strokes identified by gender and age at diagnosis

\begin{tabular}{|c|c|c|c|c|c|c|c|c|c|c|c|c|}
\hline \multirow[t]{2}{*}{ Look-back } & \multicolumn{2}{|l|}{$<65$ years } & \multicolumn{2}{|l|}{$65-74$ years } & \multicolumn{2}{|l|}{$75-84$ years } & \multicolumn{2}{|l|}{85 years+ } & \multicolumn{2}{|l|}{ Females } & \multicolumn{2}{|l|}{ Males } \\
\hline & $\begin{array}{l}\text { prevalence, } \\
\%\end{array}$ & $\begin{array}{l}\text { proportion } \\
\text { identified, } \\
\%\end{array}$ & $\begin{array}{l}\text { prevalence, } \\
\%\end{array}$ & $\begin{array}{l}\text { proportion } \\
\text { identified, } \\
\%\end{array}$ & $\begin{array}{l}\text { prevalence, } \\
\%\end{array}$ & $\begin{array}{l}\text { proportion } \\
\text { identified, } \\
\%\end{array}$ & $\begin{array}{l}\text { prevalence, } \\
\%\end{array}$ & $\begin{array}{l}\text { proportion } \\
\text { identified, } \\
\%\end{array}$ & $\begin{array}{l}\text { prevalence, } \\
\%\end{array}$ & $\begin{array}{l}\text { proportion } \\
\text { identified, } \\
\%\end{array}$ & $\begin{array}{l}\text { prevalence, } \\
\%\end{array}$ & $\begin{array}{l}\text { proportion } \\
\text { identified, } \\
\%\end{array}$ \\
\hline 1-Year & 2.6 & 31.3 & 3.0 & 21.3 & 4.6 & 27.5 & 3.4 & 21.8 & 3.6 & 25.7 & 3.4 & 24.5 \\
\hline 3-Years & 4.6 & 55.2 & 7.3 & 51.5 & 9.5 & 56.5 & 8.0 & 51.1 & 7.9 & 55.8 & 7.2 & 51.8 \\
\hline 5-Years & 6.0 & 72.4 & 10.3 & 72.8 & 12.1 & 71.8 & 10.9 & 69.8 & 10.4 & 73.3 & 9.7 & 69.8 \\
\hline 8-Years & 7.4 & 88.3 & 12.6 & 88.9 & 14.9 & 88.2 & 13.9 & 88.8 & 12.8 & 90.4 & 12.0 & 86.8 \\
\hline 10 -Years & 7.9 & 95.1 & 13.4 & 94.5 & 15.9 & 93.9 & 14.9 & 95.7 & 13.5 & 95.3 & 13.0 & 94.2 \\
\hline 12-Years & 8.3 & 100 & 14.1 & 100 & 16.9 & 100 & 15.6 & 100 & 14.2 & 100 & 13.9 & 100 \\
\hline$n$ & 1,955 & & 1,662 & & 2,517 & & 2,230 & & 4,041 & & 4,323 & \\
\hline
\end{tabular}

cases $(0.9 \%)$ were misclassified as incident strokes using a 10 -year look-back period (Table 1).

These results were similar irrespective of age or gender (Table 2; Fig. 1). Specifically, around 95\% of all recurrent strokes identified were captured using a 10-year look-back irrespective of gender or age. The prevalence of previous stroke changed by no more than $1 \%$ with a 10 - vs. 12 -year look-back across age-groups and for males and females. The prevalence of previous stroke using the maximum look-back period of 12 years was similar for females and males (14.2 and $13.9 \%)$ and varied from $8.3 \%$ for stroke cases younger than 65 years to $15.6 \%$ for those aged 85 years or older. However, in patients younger than 65 years of age, the risk of misclassifying recurrent stroke patients as incident cases was lower with shorter look-back periods compared with older patients. In patients younger than 65 years, $5.9 \%$ were misclassified as incident cases using a look-back period of 1-year. This was approximately twice that observed in patients older than 65 years (Fig. 1). This difference in misclassification between age groups was also observed for longer look-back periods of 3- and 5 -years (chi-square tests; $p<0.05 ;$ Fig. 1 ). 
Table 3. Effect of look-back period on the prevalence and misclassification of recurrent stroke classified by sub-type (ischaemic stroke ${ }^{1}$, haemorrhagic stroke ${ }^{2}$ )

\begin{tabular}{|c|c|c|c|c|c|c|c|c|}
\hline & $\begin{array}{l}\text { Number of } \\
\text { patients with } \\
\text { recurrent } \\
\text { stroke (a) }\end{array}$ & $\begin{array}{l}\text { Prevalence of } \\
\text { recurrent } \\
\text { stroke, } \\
\% \text { (b) }\end{array}$ & $\begin{array}{l}\text { Proportion of } \\
\text { recurrent stroke } \\
\text { patients } \\
\text { identified, \% (c) }\end{array}$ & $\begin{array}{l}\text { Proportion of } \\
\text { recurrent strokes } \\
\text { misclassified as } \\
\text { incident }^{3}, \% \text { (d) }\end{array}$ & $\begin{array}{l}\text { Number of } \\
\text { patients with } \\
\text { recurrent } \\
\text { stroke (a) }\end{array}$ & $\begin{array}{l}\text { Prevalence of } \\
\text { recurrent } \\
\text { stroke, \% (b) }\end{array}$ & $\begin{array}{l}\text { Proportion of } \\
\text { recurrent stroke } \\
\text { patients identified, } \\
\% \text { (c) }\end{array}$ & $\begin{array}{l}\text { Proportion of strokes } \\
\text { misclassified as } \\
\text { incident }^{3}, \% \text { (d) }\end{array}$ \\
\hline 1 year & 228 & 3.5 & 26.1 & 10.3 & 36 & 1.9 & 26.9 & 5.3 \\
\hline 3 years & 477 & 7.4 & 54.6 & 6.6 & 69 & 3.7 & 51.5 & 3.6 \\
\hline 5 years & 641 & 9.9 & 73.3 & 4.0 & 90 & 4.8 & 67.2 & 2.4 \\
\hline 8 years & 776 & 12.0 & 88.8 & 1.7 & 117 & 6.2 & 87.3 & 1.0 \\
\hline 10 years & 829 & 12.8 & 94.9 & 0.8 & 125 & 6.6 & 93.3 & 0.5 \\
\hline 12 years $(e)$ & 874 & 13.5 & 100 & 0 & 134 & 7.1 & 100 & 0 \\
\hline $\begin{array}{l}\text { Total index stroke } \\
\text { cases (f) }\end{array}$ & 6,476 & & & & 1,888 & & & \\
\hline
\end{tabular}

${ }^{1}$ ICD-10 codes I63, I64, H34.1, H34.2; 16.5\% of cases were coded as I64 (stroke, not otherwise specified).

${ }^{2}$ ICD-10 codes I60, I61, I62.9.

${ }^{3}$ The numerator is the number of patients with recurrent stroke per look-back period subtracted from the total number of patients with recurrent stroke identified using a 12 -year look-back. The denominator is the number of recurrent stroke cases identified per look-back period subtracted from the total number of ischaemic or haemorrhagic stroke cases $\{$ (e a) $/(f-a)\})$.

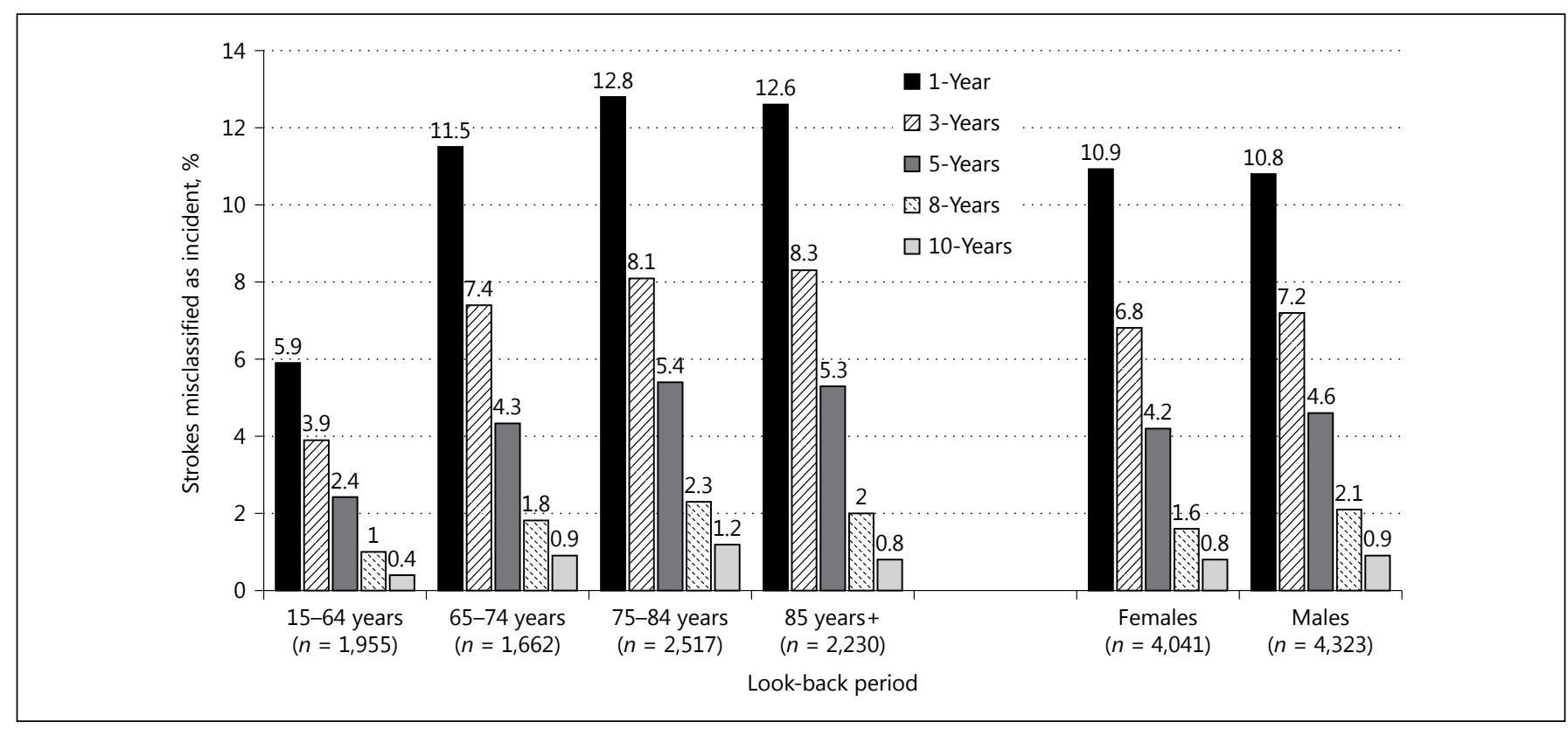

Fig. 1. Proportion of strokes misclassified as incident for each look-back period classified by age and gender.

Just over 3-quarters of cases were considered ischaemic strokes $(n=6,476 ; 77.5 \%)$ and in these patients, the prevalence of prior ischaemic stroke was $13.5 \%$ (Table 3). In contrast, $7.1 \%$ of the 1,888 patients with a haemorrhagic stroke were cases of recurrent haemorrhagic stroke. As mentioned above, a look-back period of 10 years was required to detect $95 \%$ of previous cases of ischaemic or haemorrhagic stroke. However, shorter look-back periods were associated with a statistically sig-

Differentiating Incident from Recurrent Stroke Using Administrative Data nificant lower risk of misclassification of recurrent stroke for patients with haemorrhagic stroke compared with ischaemic stroke cases. With 1-year look-back, 5.3\% of haemorrhagic strokes were misclassified compared with $10.3 \%$ of ischaemic strokes $\left(\chi_{(1)}{ }^{2}=43.9 ; p<0.0001\right)$. These respective proportions were 3.6 vs. $6.6 \%$ when using a 3-year look-back $\left(\chi_{(1)}{ }^{2}=23.6 ; p<0.0001\right.$; Table 3).

We derived "Correction factors" to adjust for missed cases of recurrent stroke per look-back period (Table 1). 
For example, the number of recurrent stroke cases can be inflated by a factor 1.285 ( $28.5 \%$ increase), when using a 5 -year look-back period.

\section{Discussion}

These results commend utilising close to 10 years of hospitalisation history when ascertaining previous stroke to minimise the risk of misclassifying patients with recurrent events as incident cases. Our analysis was specifically interested in using record linkage to capture stroke history using data from at least 10 years of previous hospitalisations. Ten percent of patients with presumed incident stroke had a prior stroke using a look-back period of 1 year to remove prevalent stroke cases, while $4 \%$ of cases identified as incident using a 5-year look-back period had experienced a recurrent event. By 10 years, the likelihood of misclassifying patients with a stroke history as an incident case was less than $1 \%$. These results indicate that estimates of incident stroke will not be appreciably affected by misclassification provided a sufficiently long clearance period is employed.

We are aware of only one other study carried out in another Australian jurisdiction (Western Australia) [25], examining the impact of varying look-back periods up to 12 and 14 years for 3,875 stroke admissions in the year 2000 and 3,740 stroke admissions in 2002 respectively. We estimated that 4 and $0.9 \%$ of presumed incident cases would be recurrent events using a 5- and 10-year lookback period, respectively, comparable with 2.4 and $0.3 \%$ reported in Western Australia. The similarity in findings between the 2 studies is noteworthy, given variations in stroke risk in Australia and over time [5, 26-30], suggesting that findings can be generalised across different populations. The authors of the Western Australian study suggested that a 5-year look-back period is adequate for identifying incident cases. However, we found that a 5 -year clearance period missed more than 1 in 4 recurrent strokes creating unacceptable levels of misclassification of recurrent stroke. This is supported by evidence from the Perth Community Stroke Study [31], which showed that 10 of the 64 recurrent strokes $(16 \%)$ recorded occurred between 5 and 10 years after incident stroke. We therefore recommend longer look-back periods when aiming to distinguish between incident and recurrent stroke and to address the epidemiology and outcomes of recurrent stroke.

We report novel findings demonstrating that the risk of misclassification was lower with shorter look-back pe- riods for patients younger than 65 years of age and for haemorrhagic stroke cases. In both sub-groups, a 1-year look-back period resulted in around 5\% of patients with recurrent stroke being misclassified as incident cases. In contrast, approximately $10 \%$ of recurrent events in other stroke patients were misclassified using a 1-year lookback period. With a 3-year look-back, the risk of misclassification in haemorrhagic stroke patients and in those younger than 65 years of age was again half that of other stroke cases. These results suggest that shorter look-back periods are appropriate for sub-groups with low baseline stroke risk, as is the case for relatively young patients and for haemorrhagic stroke.

The strengths of the study include the availability of over a decade of linked hospitalisation history, the large number of cases, the population-based ascertainment of stroke hospitalisations and the universal, health-service wide coverage of strokes in our jurisdiction, each of which minimises selection bias. We cannot be certain that these results would be replicated if we were able to apply a lookback period longer than 12-years, although Katzenellenbogen et al. [25] found minimal differences in their estimate of incident stroke whether a 12- or 14-year clearance period was applied.

We do not know how many more patients with recurrent stroke would have been identified if we could have extended the maximum look-back period beyond 12 -years. However, the estimated prevalence of recurrent stroke differed by less than $2 \%$ when applying an 8 - vs. 12 -year look-back period and by less than $1 \%$ with 10 years look-back suggesting that extending look-back periods beyond 10 -years will yield very few additional recurrent strokes. Fourteen percent of stroke patients in this statewide population were identified as having a history of stroke, which compares with similar estimates from 2 recent gold standard epidemiological studies carried out North Dublin, Ireland (14.6\%) [32] and in a rural region of one Australian state in South Australia (15.8\%) [30]. Our estimate is lower than the $21 \%$ reported in another recent study carried out in an Australian capital city (Adelaide, South Australia) [26]. In the Adelaide study, $63 \%$ of cases were older than 75 years compared with $56 \%$ in our study which at least partly explains differences between the 2 estimates as we observed higher stroke prevalence in older age groups. Gold standard epidemiological studies rely to some extent on patient and relative reports of medical history, which can lead to an over-ascertainment of previous stroke [8] and caution is often exercised to eliminate cases with a suspected stroke history, which cannot always be confirmed. In contrast, 
routinely collected data may under-numerate stroke history because coding standards specify that comorbid conditions should be noted only if the condition is actively managed in hospitals [12]. Against this, stroke sequelae impacting on patient care will be routinely coded and we would expect to capture acutely occurring strokes given the vast majority in Australia (96\%) are treated in hospital [26]. We found that around 1-in-4 cases with a stroke history were identified using sequelae codes for the varying look-back periods highlighting administrative data identify cases with both acute events and those with a stroke history.

The results reported here may depend on coding accuracy. In Australia, clinical coders review the medical record in its entirety after patient discharge recording confirmed and not provisional diagnoses. The sensitivity and accuracy of coding are enhanced in our study through capturing information on patients dying in emergency departments and the tracking of patients between hospitals eliminating reliance on provisional diagnoses made early in the patient journey at one hospital that are revised upon transfer [33]. In Australia, the accuracy of stroke coding is high. Where recorded, principal ICD-10 stroke codes (I61, I62.9, I63, I64) account for 93\% of cases recruited from participating hospitals in a registry of intracerebral haemorrhage and ischaemic stroke, indicating high levels of sensitivity and accuracy [20, 21]. Principal diagnoses are rarely missing in Australian administrative data $(0.04 \%)$ [13] and missing only in $0.3 \%$ of recorded overnight separations for acute care in our own jurisdiction [13]. The inter-rater reliability, sensitivity and PPV of clinical coding for cerebrovascular disease were found to be high in another jurisdiction when routine clinical coding was judged against an "expert" coder [19]. We are aware of 3 validation studies carried out in our own jurisdiction, 2 of which reported PPV of principal stroke diagnoses as $95 \%[29,34]$ and one study validating ICD-10 stroke codes recorded in the principal and other diagnostic positions reported a sensitivity of $85 \%$ and PPV of $86 \%$ for acute stroke [35]. One study also reviewed records with diagnoses representing potentially missed cases of stroke and found none were misclassified as false-negatives upon clinician review [29] suggesting high sensitivity. Another Australian study from outside our jurisdiction reports a PPV of $90 \%$ for acute ischaemic stroke readmissions [36].

\section{Conclusion}

Hospitalisation administrative data appears to produce valid estimates of recurrent stroke. Data linkage provides the opportunity to identify prior stroke, which is not possible with unlinked administrative data [37]. We recommend at least a 10-year look-back period to maximise the accuracy of estimates for incident and recurrent stroke. Consideration should be given to balancing the need to minimise misclassification and maximise the number of cases available for analysis, particularly where the baseline risk of stroke is low.

\section{Acknowledgements and Funding}

The authors are grateful to the Centre for Health Record Linkage for data linkage services, the NSW Ministry of Health for supplying data, and the NSW Neurological Conditions Translational Research Grants Program, NSW Ministry of Health, Office for Health and Medical Research for funding. Ethics approval was granted by the NSW Population and Health Services Research Ethics Committee (AU RED Reference: HREC/14/CIPHS/17).

\section{Disclosure Statement}

The authors have no conflicts of interest to declare.

\section{References}

1 Feigin VL, Forouzanfar MH, Krishnamurthi R, Mensah GA, Connor M, Bennett DA, et al: Global and regional burden of stroke during 1990-2010: findings from the Global Burden of Disease Study 2010. Lancet 383: 245-255.

2 Towfighi A, Markovic D, Ovbiagele B: Current national patterns of comorbid diabetes among acute ischemic stroke patients. Cerebrovasc Dis 2012;33:411-418.

3 Ramirez L, Kim-Tenser MA, Sanossian N, Cen S, Wem G, He S, et al: Trends in transient

Differentiating Incident from Recurrent Stroke Using Administrative Data ischemic attack hospitalizations in the United States. J Am Heart Assoc 2016; pii:e004026.

4 Lichtman JH, Jones SB, Leifheit-Limson EC, Wang Y, Goldstein LB: 30-Day mortality and readmission after hemorrhagic stroke among Medicare beneficiaries in joint commission primary stroke center-certified and noncertified hospitals. Stroke 2011;42:33873391.

5 You J, Condon JR, Zhao Y, Guthridge SL: Stroke incidence and case-fatality among indigenous and non-indigenous populations in the Northern Territory of Australia, 19992011. Int J Stroke 2015;10:716-722.

6 Ganesh A, Lindsay P, Fang J, Kapral MK, Côté $\mathrm{R}$, Joiner I, et al: Integrated systems of stroke care and reduction in 30-day mortality: a retrospective analysis. Neurology 2016;86:898-904.

7 Gattellari M, Goumas C, Aitken R, Worthington JM: Outcomes for patients with ischaemic stroke and atrial fibrillation: the PRISM study (a program of research informing stroke management). Cerebrovasc Dis 2011;32:370382. 
8 Woodfield R; UK Biobank Stroke Outcomes Group; UK Biobank Follow-up and Outcomes Working Group, Sudlow CL: Accuracy of patient self-report of stroke: a systematic review from the UK Biobank Stroke Outcomes Group. PLoS One 2015;10:e137538.

9 Australian Bureau of Statistics. 3101.0 Australian Demographic Statistics, March 2016. http://www.abs.gov.au/ausstats/abs@.nsf/ $\mathrm{mf} / 3101.0$ (accessed October 10, 2016).

10 Spilsbury K, Rosman D, Alan J, Boyd JH, Ferrante AM, Semmens JB: Cross border hospital use: analysis using data linkage across four Australian states. Med J Aust 2015;202:582586.

$11 \mathrm{http} / / /$ meteor.aihw.gov.au/content/index. $\mathrm{phtml} / \mathrm{itemId} / 327268$ (accessed May 12, 2016).

12 Australian Consortium for Classification Development: International Statistical Classification of Diseases and Health Related Problems and Australian Coding Standards for International Statistical Classification of Diseases and Related Health Problems: Tenth Revision, Australian Modification, 2015. Independent Pricing Authority (Ninth Edition).

13 Australian Institute of Health and Welfare 2015: Admitted Patient Care 2013-14 Australian Hospital Statistics. Health Services Series No. 60. Cat. No. HSE 156. Canberra AIHW.

$14 \mathrm{http}: / /$ www.cherel.org.au/our-services (accessed May 12, 2016).

15 Sluggett JK, Caughey GE, Ward MB, Roughhead EE, Gilbert AL: Transient ischaemic attack and ischaemic stroke: constructing episodes of care using hospital claims data. BMC Res Notes 2013;6:128.

16 Bureau of Health Information, New South Wales Ministry of Health: Spotlight on Measurement. Thirty-Day Mortality Following Hospitalisation, Five Clinical Conditions, NSW, July 2009-June 2012. Acute Myocardial Infarction, Ischaemic Stroke, Haemorrhagic Stroke, Pneumonia and Hip Fracture, December 2013. http://www.bhi.nsw.gov.au/ $\mathrm{new} / \mathrm{reports} / \mathrm{spot} \mathrm{light}$ o n measurement? $\mathrm{a}=204796$ (accessed September 13, 2016).

17 Bardach NS, Zhao S, Gress DR, Lawton MT, Johnston SC: Association between subarach- noid hemorrhage outcomes and number of cases treated at California hospitals. Stroke 2002;33:1851-1856.

18 Robertson J, Pearson SA, Attia JR: How well do NSW hospital data identify cases of heart failure? Med J Aust 2014;200:25.

19 Henderson T, Shepheard J, Sundararajan V: Quality of diagnosis and procedure coding in ICD-10 administrative data. Med Care 2006; 44:1011-1019.

20 Cadilhac DA, Lannin NA, Anderson CS, Kim J, Andrew N, Kilkenny M, Kung F, Grabsch B, et al; AuSCR Consortium: The Australian Stroke Clinical Registry Annual Report 2014. The Florey Institute of Neuroscience and Mental Health, December 2015, Report No. 6, p 65.

21 Cadilhac DA, Lannin NA, Anderson CS, Andrew N, Kim J, Kilkenny M, et al; AuSCR Consortium: The Australian Stroke Clinical Registry Annual Report 2013. The Florey Institute of Neuroscience and Mental Health, December 2015, Report No. 5, p 59.

22 Woodfield R, Grant I; UK Stroke Outcomes Group, UK Biobank Follow-up and Outcomes Working Group, Sudlow CL: Accuracy of electronic health record data for identifying stroke cases in large-scale epidemiological studies: a systematic review from the UK Biobank Stroke Outcomes Group. PLoS One 2015;10:e140533.

23 McCormick N, Bhole V, Lacaille D, AvinaZubieta JA: Validity of diagnostic codes for acute stroke in administrative databases: a systematic review. PLoS One 2015;10: e0135834.

24 MedCalc Statistical Software Version 16.8.4 (MedCalc Software bvba, Ostend, Belgium), 2016. https://www.medcalc.org.

25 Katzenellenbogen JM, Somerford P, Semmens JB, Codde JP: Effect of clearance periods on hospital stroke incidence using linked administrative data. Int J Stroke 2010;5:336337.

26 Leyden JM, Kleinig TJ, Newbury J, Castle S, Cranefield J, Anderson CS, et al: Adelaide stroke incidence study: declining stroke rates but many preventable cardioembolic strokes. Stroke 2013;44:1226-1231.

27 Islam MS, Anderson CS, Hankey GJ, Hardie $\mathrm{K}$, Carter K, Broadhurst R, Jamrozik K:
Trends in incidence and outcome of stroke in Perth, Western Australia during 1989 to 2001: the Perth Community Stroke Study. Stroke 2008;39:776-782.

28 Thrift AG, Dewey HM, Macdonell RA, McNeill JJ, Donnan GA: Incidence of the major stroke subtypes. Initial findings from the North East Melbourne Stroke Incidence Study (NEMESIS). Stroke 2001;32:1732-1738.

29 Marsden DL, Spratt NJ, Walker R, Barker D, Attia J, Pollack M, et al: Trends in stroke attack rates and case fatality in the Hunter region, Australia 1996-2008. Cerebrovasc Dis 2010;30:500-507.

30 Newbury J, Kleinig T, Leyden J, Arima H, Castle S, Cranefield J, et al: Stroke epidemiology in an Australian rural cohort (SEARCH). Int J Stroke 2017;12:161-168.

31 Hardie K, Hankey GJ, Jamrozik K, Broadhurst RJ, Anderson C: Ten-year risk of first recurrent stroke and disability after first-ever stroke in the Perth Community Stroke Study. Stroke 2004;35:731-735.

32 Kelly PJ, Crispino G, Sheehan O, Kelly L, Marnane M, Merwick A, et al: Incidence, event rates, and early outcome of stroke in Dublin, Ireland: the North Dublin Population Stroke Study. Stroke 2012;43:2042-2047.

33 Sansom LT, Ramadan H: Stroke incidence: sensitivity of hospital data coding of acute stroke. Int J Stroke 2015;10:E70.

34 Wang Y, Levi CR, Attia JR, D'este CA, Spratt $\mathrm{N}$, Fisher J: Seasonal variation in stroke in the Hunter region, Australia: a 5-year hospitalbased study, 1995-2000. Stroke 2003;34: 1144-1150.

35 Ghia D, Thomas PR, Cordato DJ, Worthington JM, Cappelen-Smith C, Griffith N, et al: Validation of emergency and final diagnosis coding in transient ischemic attack: South Western Sydney transient ischemic attack study. Neuroepidemiology 2010;35:53-58.

36 Lee AH, Somerford PJ, Yau KK: Risk factors for ischaemic stroke recurrence after hospitalisation. Med J Aust 2004;181:244-246.

37 Roussot A, Cottenet J, Gadreau M, Giroud M, Béjot Y, Quantin C: The use of national administrative data to describe the spatial distribution of in-hospital mortality following stroke in France, 2008-2011. Int J Health Geogr 2016;15:2. 